\title{
Detection of Network Instability using Area-Based Centre of Inertia-Referred Frame
}

\author{
P. F. Le Roux ${ }^{1}$ - R. C. Bansal ${ }^{1}$ (I)
}

Received: 21 March 2017 / Accepted: 6 November 2017 / Published online: 28 November 2017

(C) Springer Nature Singapore Pte Ltd. 2017

\begin{abstract}
The operation of electrical networks constantly face contingencies such as generation outages and line faults. When a network is running under high stress levels or a transient fault occurs, the network might undergo angle instability. As a result, the network splits into several islands causing great loss of load and generation thus, creating network instability and a potential blackout. In this paper Center of Inertia (COI) as well as each area is used for the detection of network instability where the rotor angle stability of the entire network is monitored to establish if and when the network becomes unstable. The method is implemented on the IEEE 39-bus system known as the 10-machine New-England Power System.
\end{abstract}

Keywords Transient stability · Phase angle $\cdot$ Rotor angle $\cdot$ Center of inertia (COI) $\cdot$ Phasor measurement units $\cdot$ Smart Grid

\section{Introduction}

Power system stability was identified as a problem in the early 1920's where loads were fed remotely from long distances. Transient stability is defined by the ability to keep the network in synchronism after a large transient disturbance occurs in the network. There are different types of network disturbances, namely: i) overhead line faults, ii)

R. C. Bansal

rcbansal@ieee.org

1 Department of Electrical, Electronics and Computer Engineering, University of Pretoria, Pretoria, South Africa loss of load, iii) loss of generation and iv) loss of transformers [1]. Transient stability is one of the most

important aspects to take into consideration while doing a power system design. Transient stability occurs in a very small time frame, making it impossible for an operator to mitigate the problem. This is why transient stability should be considered in the design phase of the network [1-3].

The world has seen rapid growth with various developments to the electrical grid in the past century trying to create a sufficient and more reliable grid called the "Smart Grid". It consists of various techniques where monitoring and controlling of the network stability is one of the most important. The "Smart Grid" consists of two parts in the energy management system, namely: i) The foundation and ii) the fundamental applications where the foundation can be divided into several parts, namely: Infrastructure, Telecommunication Infrastructure and Circuit Topology. Fundamental applications can also be divided into sub-sections: smart meters, meter data management system, distribution automation, distribution management system and substation automation $[4,5]$.

Network instability is of big concern and one of the key problems the industry are facing today. As a result, instability in networks might lead to downfall of voltage and cause blackouts. Several blackouts have occurred in the past in different parts of the world [6] which can be prevented by using various technique, namely: generator excitation control, generator tripping schemes, braking resistors, fast valving, eliminating time, removal of charge and series capacitors [7]. There are several techniques to detect and control transient instability such as: to solve the state space differential equations [7], direct methods for example: i) area based COI-referred frame and ii) the energy function concept [8], catastrophe theory [9], artificial 
neural networks [10], pattern recognition techniques [11] and hybrid techniques combining neural networks and pattern recognition [12], etc.

Ree et al. [13] have discussed typical uses of synchrophasors, namely: monitoring and controlling of power networks. By monitoring the power networks, analysts may analyse the exact sequence of events to find out what has led to the event. Synchrophasor real time data can be retrieved from phasor measurement units at different parts of the network or national grid to monitor and calculate specific network controls if and when needed [14].

Operation of electrical networks constantly faces contingencies such as generation outages and line faults. A survey on different voltage instability detection methods were presented by Glavic et al. [15]. Voltage instability detection has two approaches namely: i) data concentrated at one location and ii) wide-area monitoring. Ning et al. [6] proposed several methods to monitor the stability of power networks in real-time namely: i) monitoring damping levels, small signal stability (SSS), ii) voltage security indices, and iii) angle instability indicators. The authors [6] have used synchrophasors to transmit data from one point to the next making real time monitoring possible. For voltage security monitoring, the authors have defined the voltage security assessment index as the slope of the $\Delta \mathrm{QV}$ curve of each bus where $\Delta \mathrm{Q}$ represents the change of reactive power and $\Delta \mathrm{V}$ the change in voltage of each bus. The power system becomes voltage insecure at the specific bus when the index approaches zero. By paralleling the voltage security indexes of all the busses in the network, the bus with the lowest security index is the bus most likely to become unstable.

Schweitzer et al. [16] have emphasized, to accomplish several system stability applications by using synchrophasors, namely: i) detecting out-of-step (OOS) conditions, ii) identifying inter-area power oscillations, iii) protecting multi-terminal substation bus-bars and iv) identifying current and voltage measurement errors. Mulhausen et al. [17] have developed a wide-area monitoring scheme based on the island detection scheme that uses synchrophasor technology to calculate the slip frequency and the acceleration between the systems. The scheme has multiple benefits compared to the traditional scheme especially when the power mismatch is minimal [18].

$\mathrm{Hu}$ et al. [19] developed algorithms that detect the fast separation of the phase angles in a network by means of synchrophasor data collected by phasor measurement units (PMUs) at selected busses. When the system becomes unstable, the best suitable action is taken for example: tripping of critical generators or load shedding. The two algorithms were based on the phase angle and the energy function concept approach. For the phase angle method, the Center-of-Inertia (COI) referred frame was used to determine whether the generators were accelerating or decelerating away from the network. When a generator exceeded a threshold, generator tripping (acceleration of angle) or load shedding (decelerating of angle) was implemented. Sherwood et al. [8] gave an explanation of the phase angle method as well as a thorough explanation on the energy function concept. The energy function concept was formulated in a similar way to the phase angle algorithm. The results indicated if the generators were accelerating or decelerating away from the network. Sherwood et al. [8] extended research work presented in [6] by adding the Hamilton's Principle of Least Action algorithm. The Action and Lagrangian quantities were also calculated by means of synchrophasor data where the potential and kinetical energy calculations were used to predict early instability in the network. By implementing these algorithms and creating decent thresholds for network instability, the critical clearing time was improved.

Wahab et al. [20] have substantiated that the COI-referred area based technique can successfully detect transient instability when a fault occurs by determining the weakest area in a power network. A combined control scheme called Under Frequency Load Shedding (UFLS) with Generator Tripping was proposed. Although UFLS is a very good control scheme, researchers [20] aimed to decrease the amount of load being shed and still stabilize the network. With this, researchers first introduced generator tripping and observed that when the most critical generator (first generator to go out-of-step) was tripped, less load needed to be shed. It was further noted that when the proposed method was implemented, the rotor angle deviation of the network was lower thus; lower stress was exerted on the generators of the network. For generator tripping, Wahab et al. [20] determined the weakest area of the network by using the COI-referred frame index. When the weakest area in the network was established, the individual generator within that specific area to go out-of-step first was searcher for. Hashim et al. [21] also based their research on the rotor angle method but, included the rotor speed of the generators in each area. The researchers [21] found that when the COI speed of each area goes above a certain threshold, the generators lose synchronism and go out-of-step.

Karady et al. [22] carried out research on the generator tripping field and developed a hybrid method consisting of an online as well as an off-line prediction method. For the online prediction of transient stability researchers [22] used a polynomial curve fitting technique and then developed an off-line shell program that generates and updates a lookup table of generator tripping requirements to help speed up the decision making process. By combining these techniques a hybrid method was developed that could avoid any unnecessary tripping. Baydokhty et al. [23] have developed 
a fuzzy based control system for effective generator tripping that consisted of two parts: a look-up table for the prediction of rotor angle instability and the other used for training of the algorithm. MATLAB and Dig-Silent software were used to develop this technique to improve on the traditional generator tripping method and to prevent over-tripping of generators.

An Immune Algorithm, similar to the Genetic Algorithm, was used to calculate a proper generator tripping plan for a special protection system (SPS). This was done to avoid transient instability of N-3 contingencies for the Taiwan Power System. The algorithm was developed by Chen et al. [24] to select the optimal generator tripping solution to keep the network from becoming unstable. Wang et al. [25] did transient stability assessment using Catastrophe Theory. Center-of-Inertia (COI) approach was used to determine the radians difference between two generator groups and used Catastrophe Theory to study the system operational discontinuity.

This research focuses on the detection of network instability and implementing a control scheme to stabilize the network and prevent network instability. The proposed methodology is tested on IEEE-39-bus network. The centerof-inertia (COI) referred frame is used for the detection of network instability, the critical clearing time (CCT) method to determine the thresholds when a control should be implemented to maintain network stability and finally a control scheme to stabilise the network. By combining these methods by programmed scripts using MATLAB software, the simulation is more flexible and more accurate. The research was extended by simulating faulty PMUs at different locations while a transient fault was created and rectified with a control to prove the stability and performance of the proposed method.

\section{Proposed Methodology}

\section{Phase Angle Algorithm}

Assuming all generators in each area are running in synchronism before any fault conditions and one single generator represents all the generators in that area. By using the area based COI-referred frame method it is possible to track the stability of a power system.

The algorithm used is based on the research carried out in [6] where the phase angle measurements were used to calculate instability in the IEEE two-area network where as in this research, all simulations were based on the IEEE 39bus network. The phase angle algorithm is executed in two stages: i) calculation of the angle stability in each area of the network, and ii) calculation of the angle stability in the entire network. The area based COI-referred frame method can be formulated as seen in Eq. 1:

$\delta_{C O I}=\frac{\sum_{i=1}^{N} \bar{\delta}_{i} H_{i}}{\sum_{i=1}^{N} H_{i}}$

where $\mathrm{H}_{\mathrm{i}}$ is the inertia constant, $\bar{\delta}_{\mathrm{i}}$ is the rotor angle and $\mathrm{N}$ are the total number of areas. In practice it is difficult to measure the rotor angle of a generator. In order to achieve this, a phasor measurement unit (PMU) needs to be installed at each generator in the power system to determine the rotor angle of each generator. Although the inertia of a generator is a constant and can easily be obtained, Eq. 1 cannot be used if the rotor angle is not available. Because of this, the high voltage side phase angle may be used as an approximation to the rotor angle; where the inertia of the generator can be approximated by the active power injections at the high voltage side of the generator. By using the voltage phase angle and the active power of each generator, the formulation of each area can be written as:

$\delta_{c}^{i}=\frac{\sum_{j=1}^{N} \delta_{j}^{i} P_{j}^{i}}{\sum_{j=1}^{N} P_{j}^{i}}$

where $\delta_{j}^{i}$ and $P_{j}^{i}$ denote the phase angle and the active power at bus $j$ and area $i$. This will be the same when calculating the COI-referred frame for the entire system:

$\delta_{c}=\frac{\sum_{i=1}^{N} \delta_{c}^{i} P^{i}}{\sum_{j=1}^{N} P_{j}^{i}}$

The equivalent rotor angle of each area can be expressed in the COI-referred frame:

$\delta_{j}^{C O I}=\delta_{c}^{i}-\delta_{c}$

These measurements are retrieved from phasor measurement units at selected areas in the power network. By increasing the number of PMUs in the system, more accurate referred angle can be obtained. These measurements are then concentrated at a central point by using synchrophasor technology where the data can be monitored and used for technical analysis.

When the COI angle $\delta_{c}^{i}$ of each area starts to increase beyond a certain threshold from the COI angle $\delta_{c}$ for the entire network, it can be said that area $i$ is moving away from the entire network. When generators are separated from their networks, there are two main controls that can be implemented, namely: i) generator tripping and ii) load shedding. Once the generator angle increases (accelerates) away from the network beyond a threshold, generator tripping can be implemented. When the generator angle decreases (decelerates) beyond a threshold, load shedding can be implemented. 


\section{Illustration of Phase Angle Algorithm}

For demonstration purposes, the IEEE two area network as shown in Fig. 1 is used [19]. The IEEE two area network consists of: i) 4 generators, ii) 12 overhead lines and iii) 13 busses.

By dividing the IEEE two area network, generator one and generator two in one area and generator three and generator four in the second area, the COI-referred frame of each area can formulate [20]:

$\delta_{c}^{1}=\frac{\delta_{1}^{1} P_{G 1}+\delta_{2}^{1} P_{G 2}}{P_{G 1}+P_{G 2}}$

$\delta_{c}^{2}=\frac{\delta_{3}^{2} P_{G 3}+\delta_{4}^{2} P_{G 4}}{P_{G 3}+P_{G 4}}$

$\delta_{c}=\frac{\delta_{1}^{1} P_{G 1}+\delta_{2}^{1} P_{G 2}+\delta_{3}^{2} P_{G 3}+\delta_{4}^{2} P_{G 4}}{P_{G 1}+P_{G 2}+P_{G 3}+P_{G 4}}$

where Eq. 5 is the COI-referred frame formulated for area 1, Eq. 6 is for area 2 and Eq. 7 is for the entire system. The area equivalent rotor angles can now be expressed as:

$\Delta \delta_{c}^{1}=\delta_{c}^{1}-\delta_{c}, \Delta \delta_{c}^{2}=\delta_{c}^{2}-\delta_{c}$

\section{Results and Discussion}

\section{Implementation of the Proposed Algorithm}

The proposed algorithm was implemented on the IEEE 39bus system, also known as the 10-machine New-England power system. The IEEE 39-bus system consists of: i) ten generators, ii) twelve transformers, iii) forty six overhead lines and iv) nineteen loads.
The purpose of this research is to obtain the dynamic rotor angle performance of each generator in its respective area in the power system during disturbances with a time domain simulation technique. In order to simulate the rotor angle's behaviour, three phase faults were simulated at different locations in the network. This was done in order to see if and when a generator goes out-of-step (OOS). When a three phase fault is created on a specific overhead line in the network, the local and remote circuit breaker of the line will open and isolate the line.

If a rotor angle of a generator exceeds $\pm 180^{\circ}$ in approximately two seconds the network becomes unstable, otherwise the network remains stable [20]. This was proven to be a very practical method in previous years. The area-based COI-referred frame technique is used to detect the weak areas in the network in advance where corrective actions can then be performed to keep the network stabilized, i.e., generator tripping or load shedding.

Figure 2 shows the IEEE 39-bus network divided into three areas. The areas were selected according to the generators' coherency when exposed to a fault condition [26].

A fault was simulated at four different overhead lines with a fault time duration of $100 \mathrm{~ms}$. These four cases were specifically chosen to achieve different scenarios for illustration purposes from the IEEE-39-bus network. The case studies in this section are used to prove the robustness and accuracy of the COI-referred frame that is used to indicate the stability of the network. The rotor angle of each area in the network is plotted and discussed:

Case 1: For the first case study shown in Fig. 3, a three phase fault was simulated at the overhead line between bus 26 and bus 27 in area 1 of the IEEE 39-bus system shown in Fig. 2. The local and
Fig. 1 IEEE Two Area Network [18]

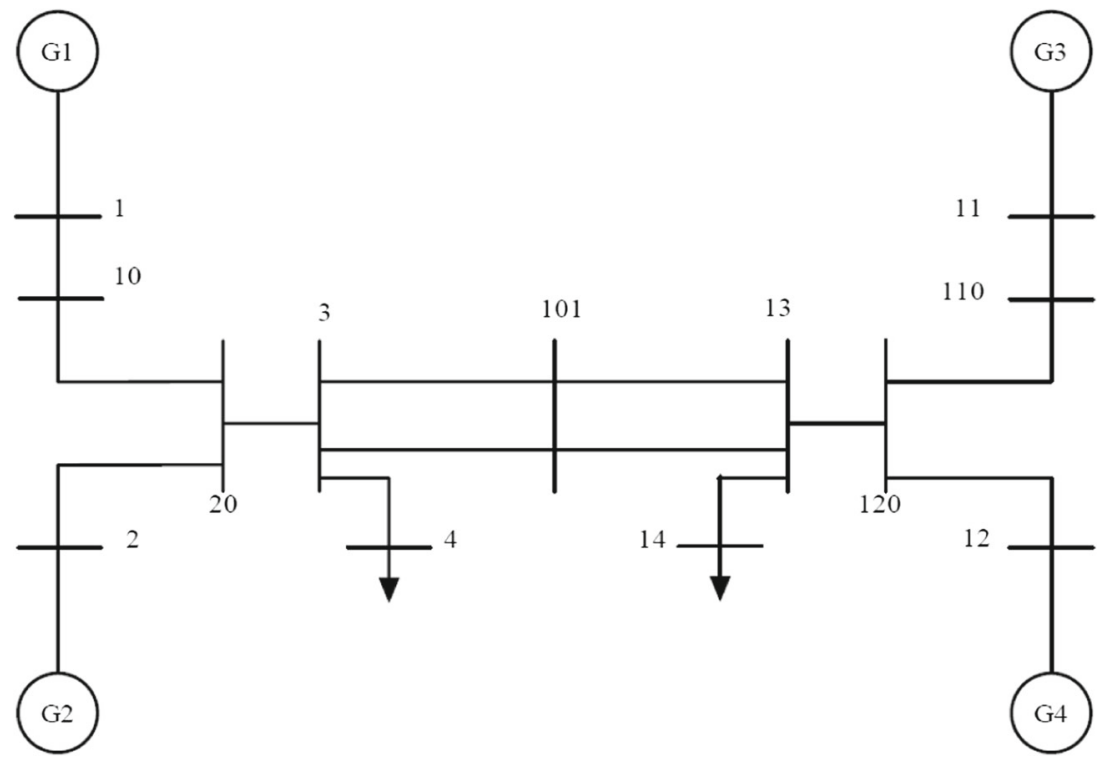


Fig. 2 IEEE-39-Bus Network Areas

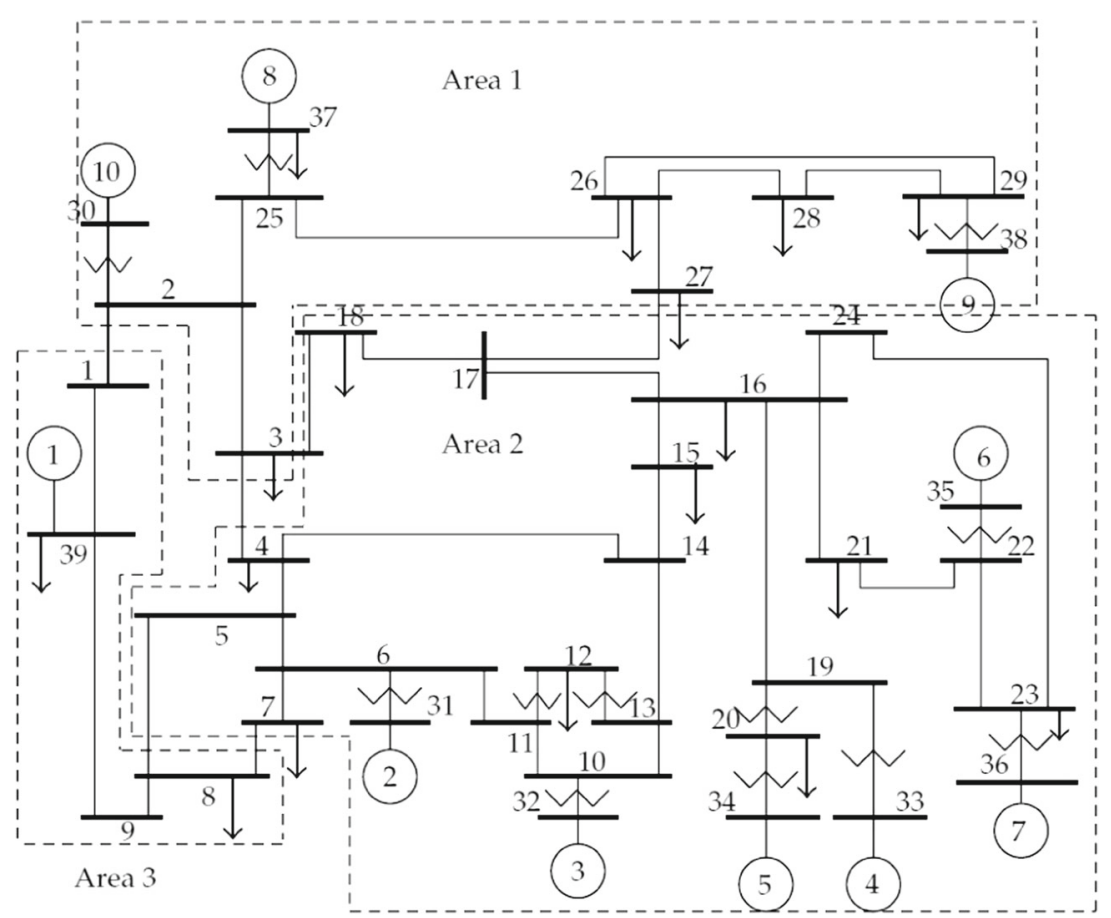

remote circuit breakers of the overhead line were opened after the fault was cleared at $100 \mathrm{~ms}$. It is clear that the rotor angles of all three areas do not exceed $\pm 180^{\circ}$ and oscillate thus, the network remains in its stable state.
Case 2: For the second case study shown in Fig. 4, a three phase fault was simulated at the overhead line between bus 8 and 9 in area 3 (Fig. 2). The local and remote circuit breakers on the overhead line were opened after the fault was cleared at $100 \mathrm{~ms}$.

Fig. 3 Case 1: Stable

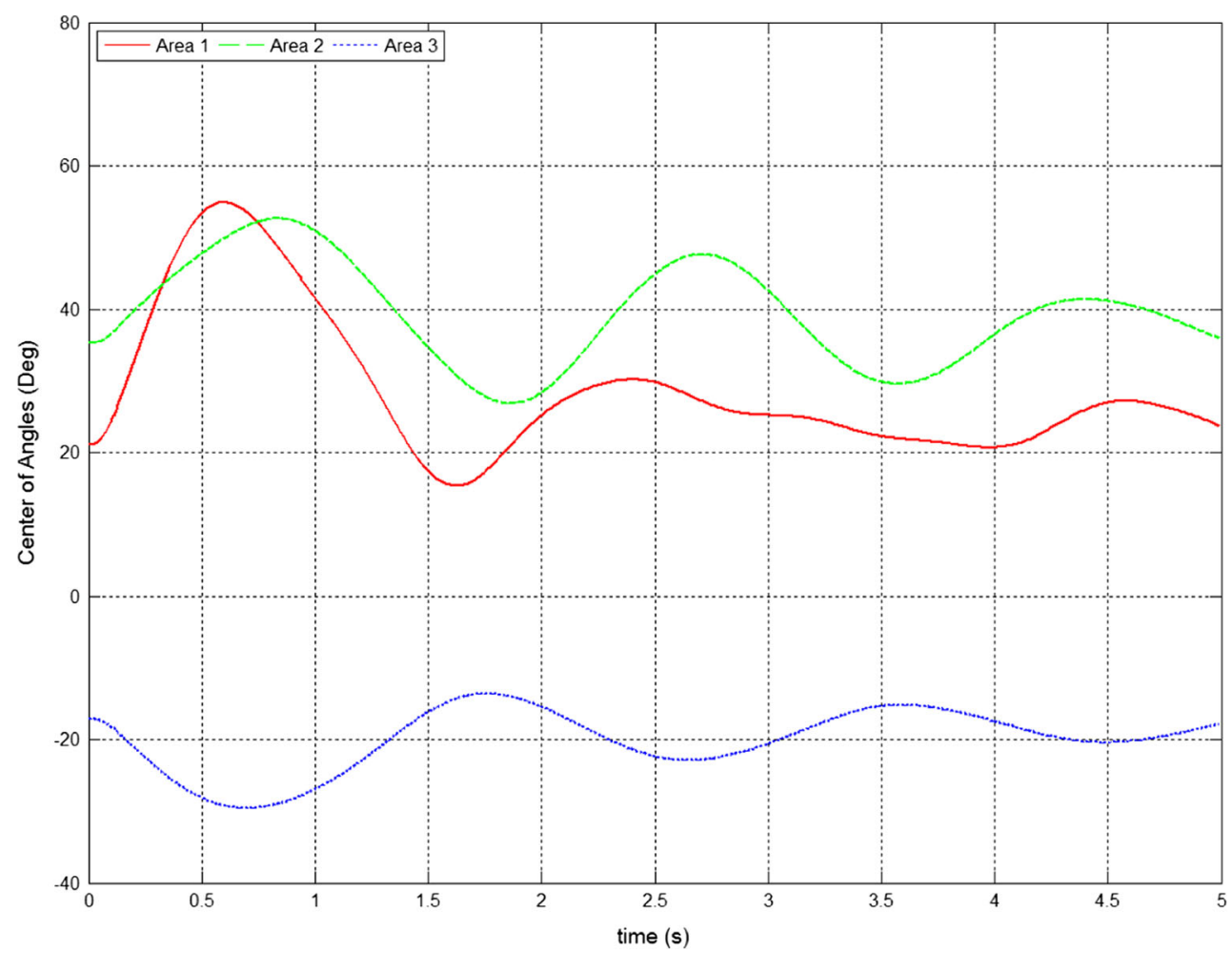


Fig. 4 Case 2: Stable

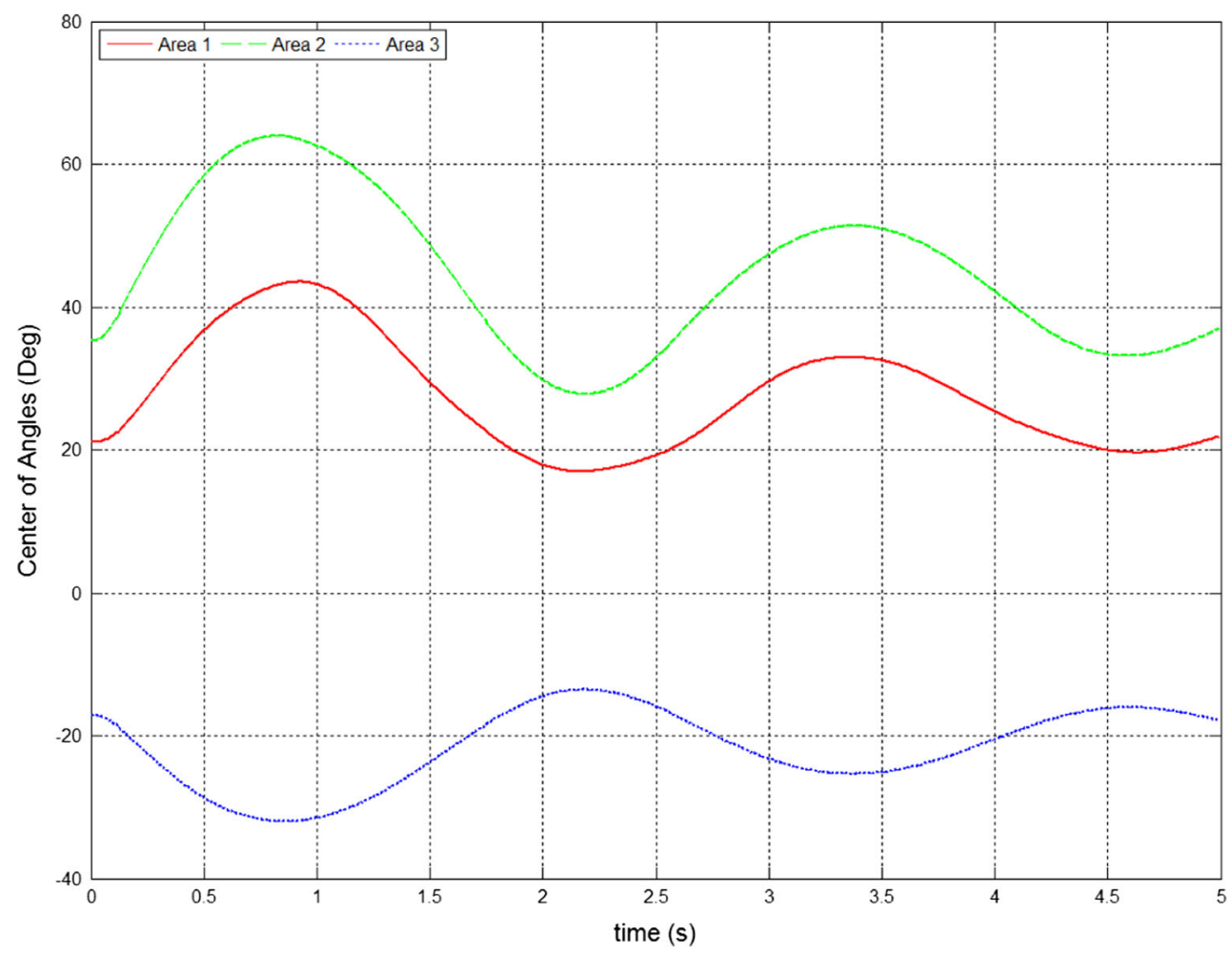

It is clear that the rotor angles of all three areas do not exceed $\pm 180^{\circ}$ and oscillate thus, the network remains in its stable state.

Case 3: For the third case study shown in Fig. 5, a three phase fault was simulated at the overhead line between bus 16 and bus 17 in area 2 (Fig. 2). The local and remote circuit breakers on the overhead line were opened after the fault was cleared at $100 \mathrm{~ms}$. Area 1 and area 2 increased exponentially whereas area 3 decreases. By analysing Fig. 5, it

Fig. 5 Case 3: Unstable

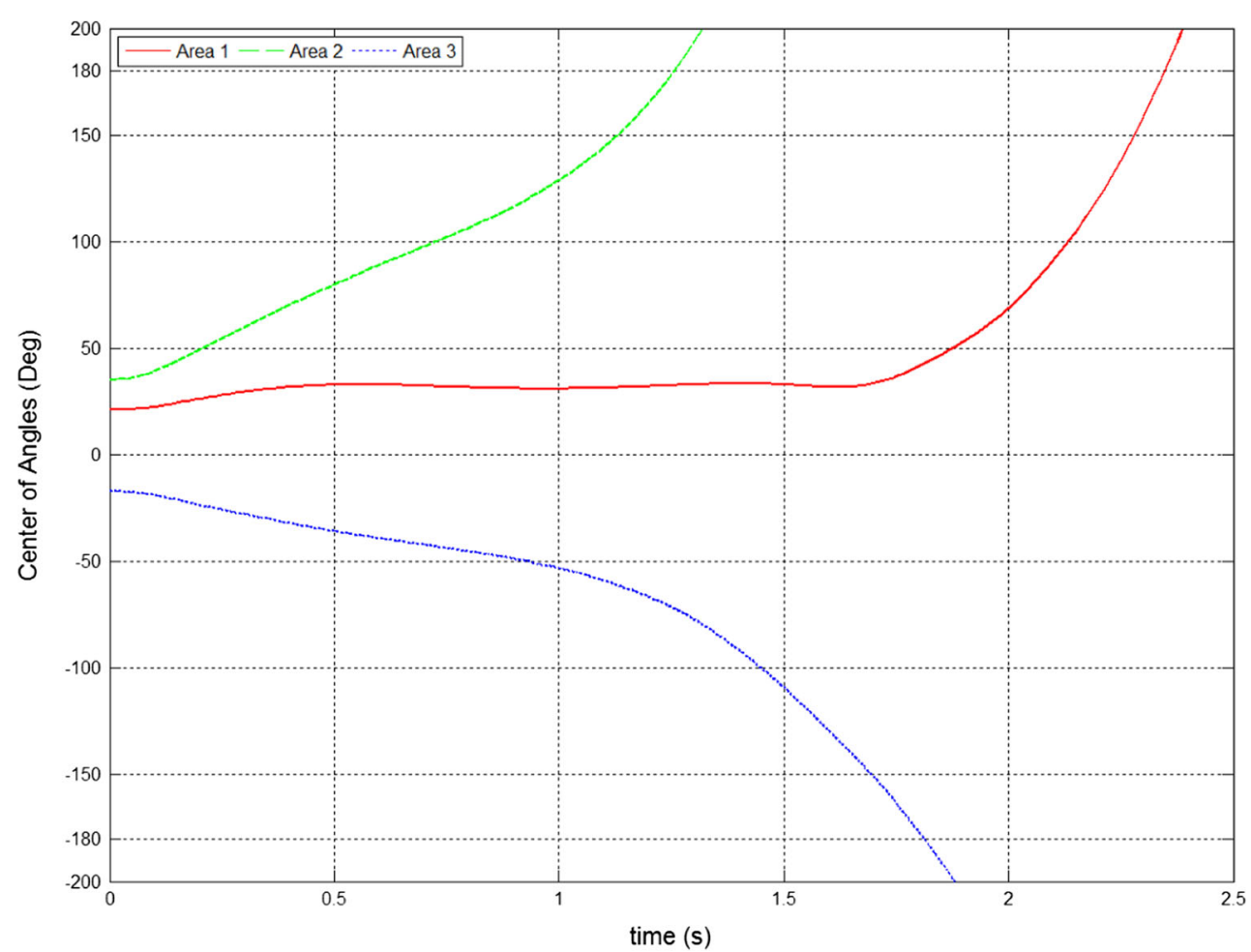


Fig. 6 Case 4: Unstable

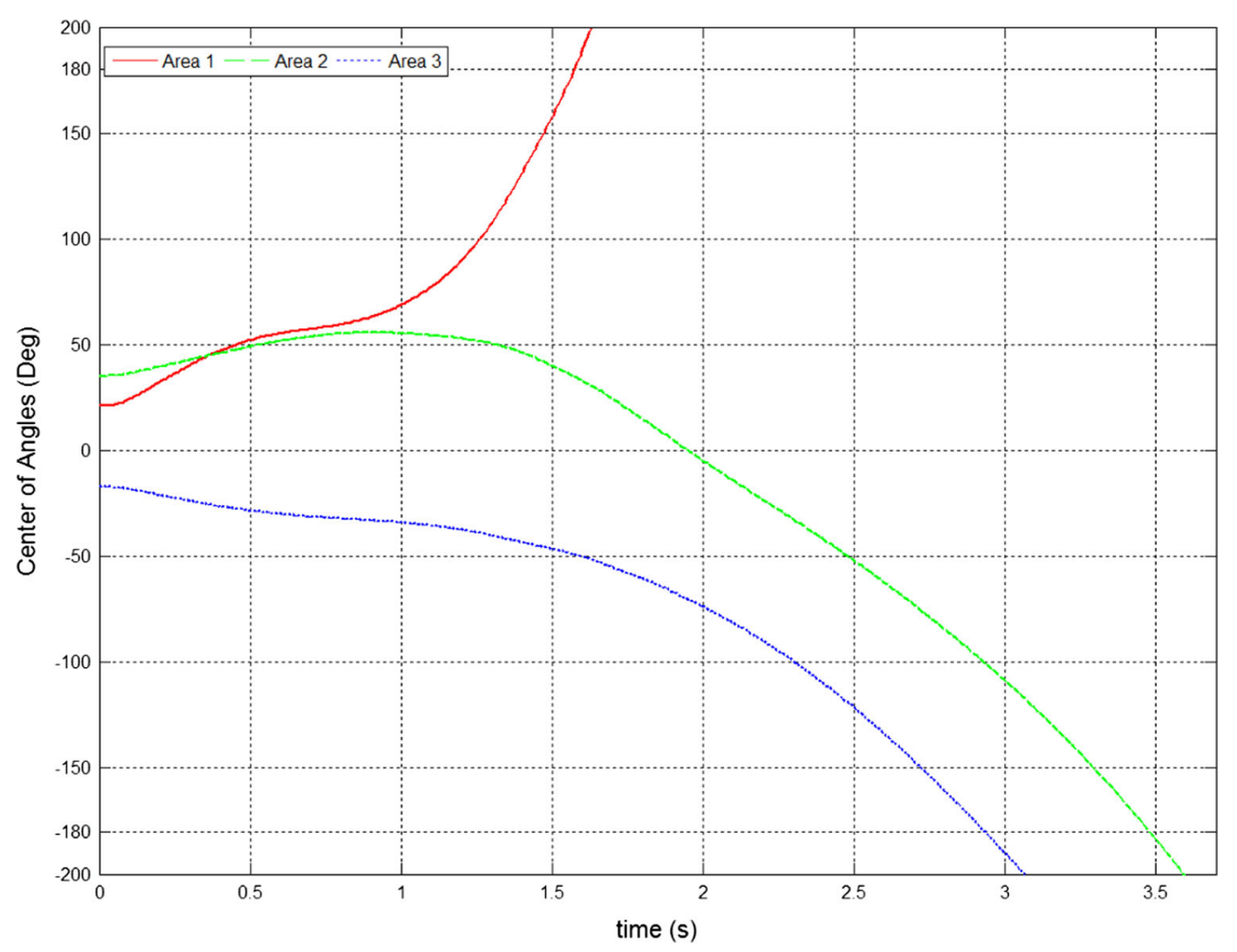

Fig. 7 Angles of areas at $40 \mathrm{~ms}$ clearing time

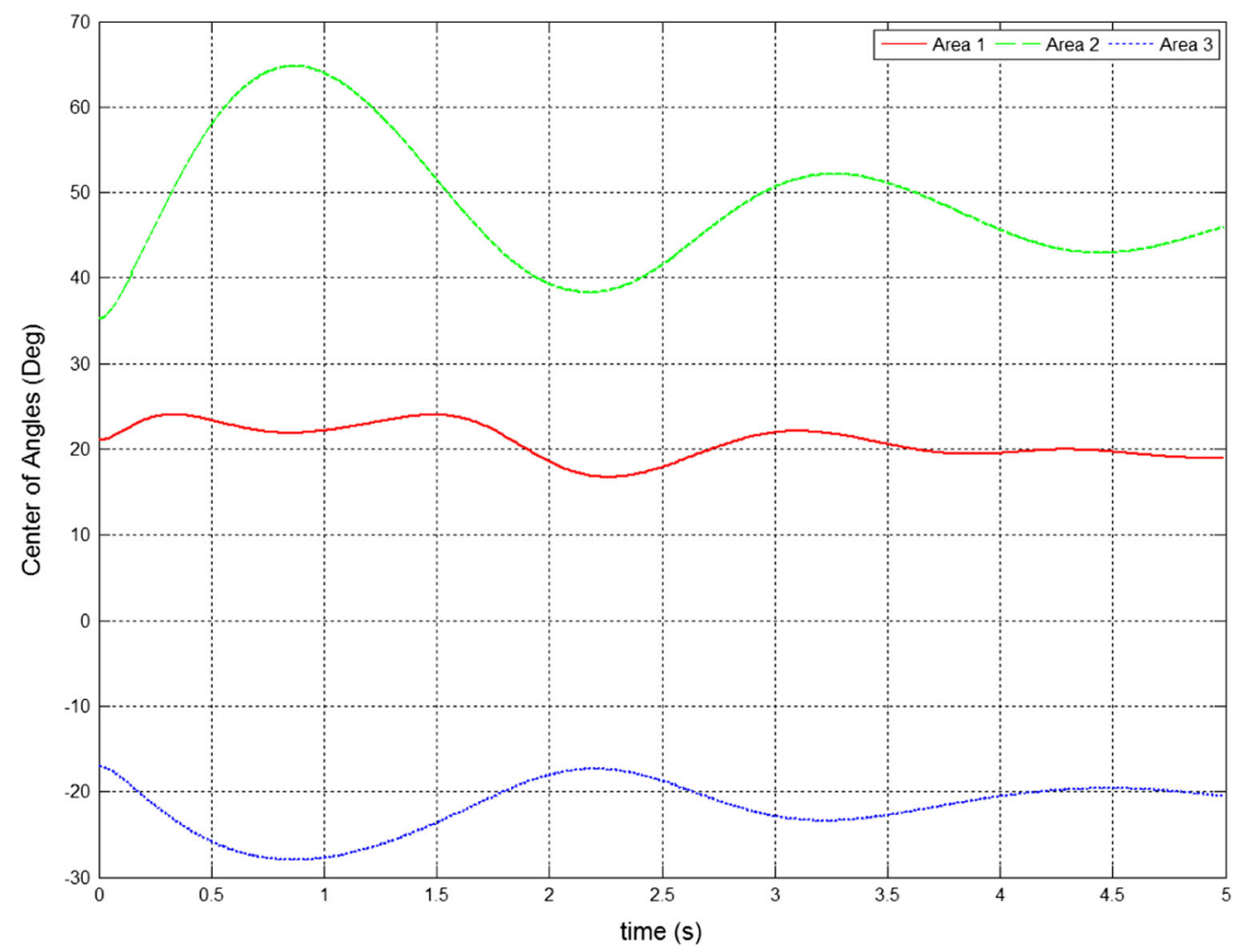


can be seen that area 2 went out of step (OOS) first thus, making it the weakest area in the network.

Case 4: For the fourth case study shown in Figs. 6 and 7, a three phase fault was simulated at the overhead line between bus 26 and bus 29 in area 1 (Fig. 2). The local and remote circuit breakers on the overhead line were opened after the fault was cleared at $100 \mathrm{~ms}$. Area 1 increased exponentially whereas area 2 and area 3 decreases. By analysing Figs. 6 and 7, it can be seen that area 1 went out of step (OOS) first at $1.58 \mathrm{~s}$ thus, making it the weakest area in the network.

\section{Determining the Critical Clearing Time}

When a fault occurs, the network can stay stable or become un-stable depending on the type and duration of the fault. The critical clearing time (CCT) in a power system is the maximum time a fault can occur without becoming unstable. By simulating different three-phase fault durations, the CCT can be found for each overhead line.

For illustration purposes Case 3 will be used to find its CCT. When the fault clearing time (local and remote) is set to be $40 \mathrm{~ms}, 50 \mathrm{~ms}$, and $60 \mathrm{~ms}$, the curves of $\Delta \delta_{c}^{1}, \Delta \delta_{c}^{2}$ and $\Delta \delta_{c}^{3}$ are shown in Figs. 7, 8 and 9, respectively.

From the study above, the CCT can be said to be $50 \mathrm{~ms}$ from the three phase fault simulated at the overhead line between bus 16 and bus 17 in area 2 (Fig. 2). The CCT is
$50 \mathrm{~ms}$ because, if the fault duration is more than $50 \mathrm{~ms}$ and if not isolated in this specific time frame, the power system becomes unstable as seen in Fig. 9 where the time duration is $60 \mathrm{~ms}$. Thus, by analysing Fig. 8, the supreme value of $\Delta \delta$ is equal to $73^{\circ}$ and the least value of $\Delta \delta$ equal to $-31^{\circ}$ for the critical stable case.

\section{Detecting Angle Instability using a Heuristic Rule}

As previously discussed, when the COI angle $\delta_{c}^{i}$ of each area increases beyond a certain threshold from the COI angle $\delta_{c}$ of the entire network; we can say that area $i$ is moving away from the entire network. In this case, generator tripping or load shedding controls can be implemented. Once the generator angle increases away from the network beyond a threshold, generator tripping can be implemented. When the generator angle decreases beyond a threshold, load shedding can be implemented.

The voltage algorithm concept was used to create the heuristic trigger control [27]. To determine if the speed of the generators are increasing or decreasing (accelerating or decelerating), two integral terms $\Omega_{a}^{i}$ and $\Omega_{d}^{i}$ were created for Area $i$. The term $\Omega_{a}^{i}$ is the integral of the phase angle for $\delta_{c}^{i}$ when the phase angle of the area stays above a certain threshold $\delta_{c}^{i^{*}}$. The term $\Omega_{a}^{i}$ is reset to zero when $\delta_{c}^{i}$ goes below the threshold $\delta_{c}^{i *}$.

When $\Omega_{a}^{i}$ grows beyond a specific threshold value $\Omega_{a}^{i^{*}}$, it can be said that area $i$ is accelerating away from the power
Fig. 8 Angles of areas at $50 \mathrm{~ms}$ clearing time

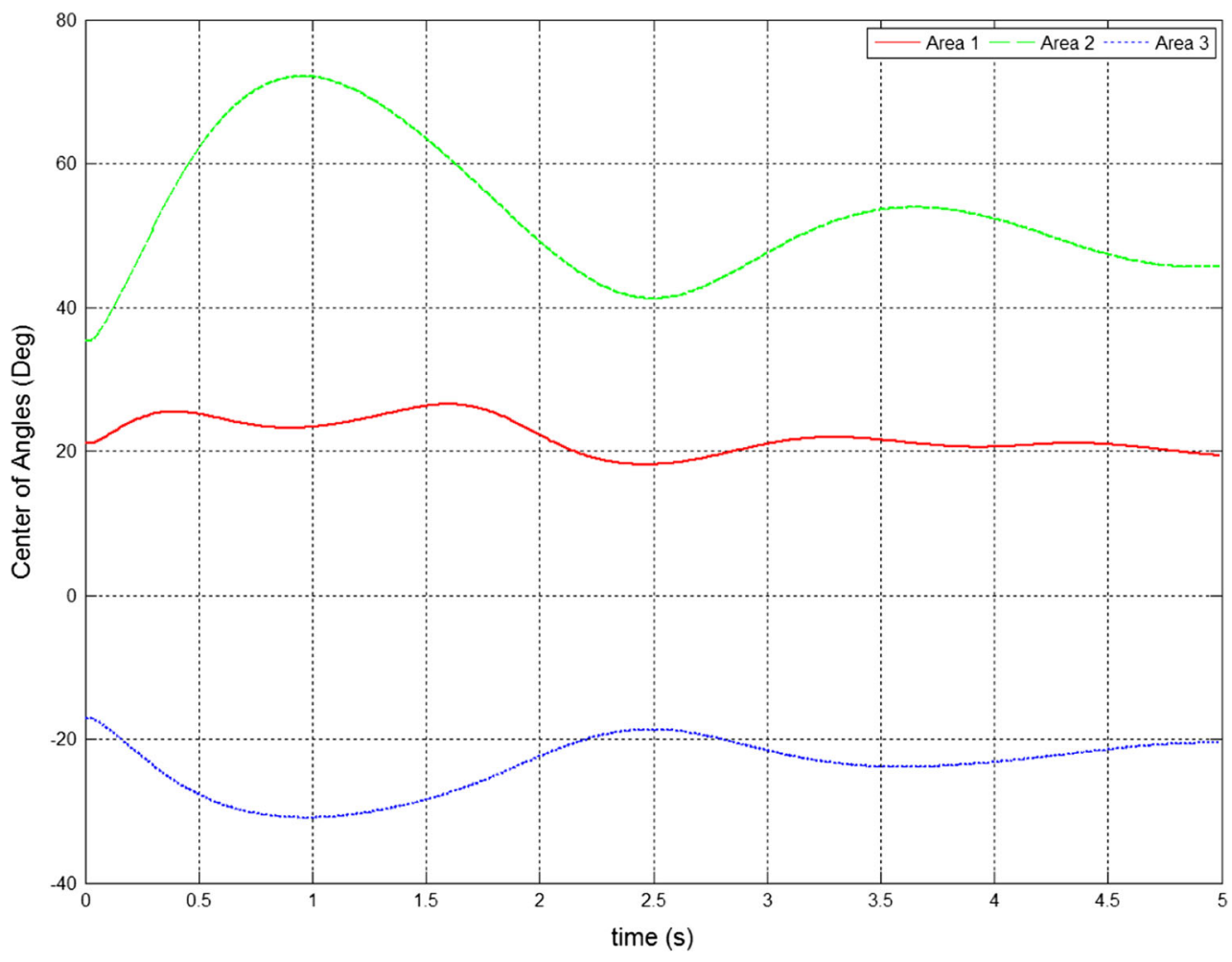


Fig. 9 Angles of areas at $60 \mathrm{~ms}$ clearing time

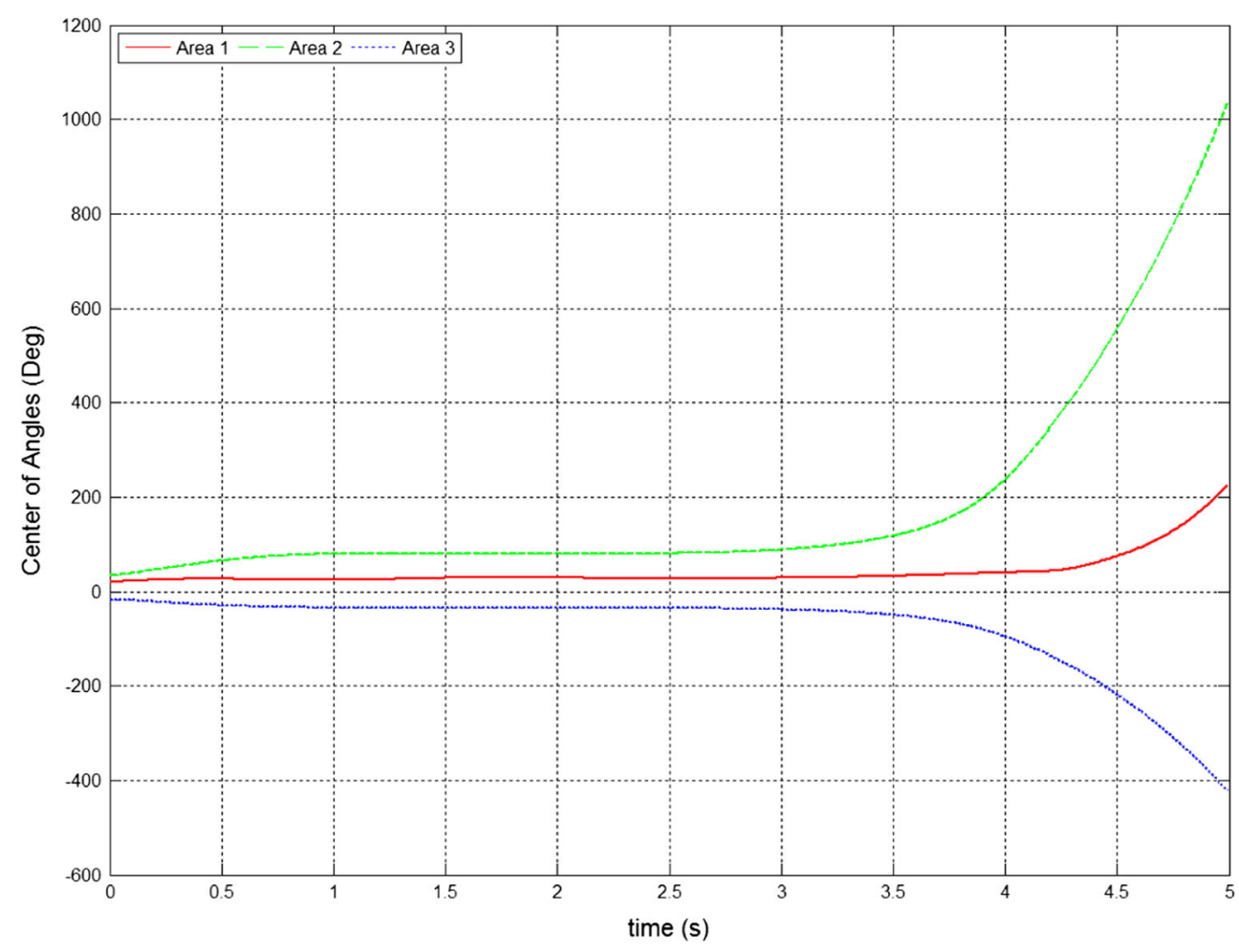

system. Thus, generator tripping can be initiated in the specific area to stabilize the network. The value of $\Omega_{a}^{i^{*}}$ needs to be fine-tuned with each different power system because of the total generating power and current spinning reserve in each area. The less the current spinning reserve, the lower the threshold value of $\Omega_{a}^{i^{*}}$.

The computation of a decelerating area will work on the same principles than the accelerating area. When $\Omega_{d}^{i}$ goes beyond a specific threshold value $\Omega_{d}^{i^{*}}$, it can be staid that area $i$ is decelerating away from the power system. Thus, load shedding can be initiated in the specific area to stabilize the network. The value of $\Omega_{d}^{i *}$ will have to be fine-tuned with each different power system because of the total generating power and current spinning reserve in each area. The less the current spinning reserve, the lower the threshold value of $\Omega_{d}^{i^{*}}$.

In Section "Detecting Angle Instability using a Heuristic Rule" we proved that the CCT can be said to be $50 \mathrm{~ms}$ from the three phase fault created at the overhead line between bus 16 and bus 17 in Area 2 (Fig. 2). As seen in Fig. 8, the supreme value of $\Delta \delta_{c}^{2 *}$ equal to $73^{\circ}$ and the least value of $\Delta \delta_{c}^{3 *}$ equal to $-31^{\circ}$ for the critical stable case.

Where, start (s) is the time the phase angle $\Delta \delta_{a}^{i}$ increases beyond $\Delta \delta_{a}^{i *}$ and control (s) is the time $\Omega_{a}^{i}$ reaches $\Omega_{a}^{i *}$.

Table 1 shows different fault-on times. By studying these results, it is clear that area 2 will be the first area to move away from the power system. Area 2 is accelerating away from the network thus, generator tripping should be implemented. Area 3 is the second area to move away from the power system. Area 3 is decelerating away from the network thus; load shedding should be implemented if the network does not recover after the generator tripping control was implemented.

Because we know that area 2 will be the first area to go OOS, we need to do further investigation in area 2 to find the critical generator. In Fig. 10 we can see that all the generators go OOS (solid/dash lines), generator 5 is indicated with a dashed line that will go OOS first.

Table 1 Case 3 results for the IEEE 39 bus network

\begin{tabular}{|c|c|c|c|c|c|c|c|c|}
\hline \multirow{3}{*}{$\begin{array}{l}\text { Fault-on Time } \\
\text { Result } \\
\text { Area }\end{array}$} & \multirow{3}{*}{$\begin{array}{l}40 \mathrm{~ms} \\
\text { Stable } \\
-\end{array}$} & \multirow{3}{*}{$\begin{array}{l}50 \mathrm{~ms} \\
\text { Stable } \\
-\end{array}$} & \multirow{2}{*}{\multicolumn{3}{|c|}{$\begin{array}{l}60 \mathrm{~ms} \\
\text { Unstable }\end{array}$}} & \multirow{2}{*}{\multicolumn{3}{|c|}{$\begin{array}{l}70 \mathrm{~ms} \\
\text { Unstable }\end{array}$}} \\
\hline & & & & & & & & \\
\hline & & & Area 1 & Area 2 & Area 3 & Area 1 & Area 2 & Area 3 \\
\hline Start (s) & - & - & 4.23 & 0.62 & 0.702 & 2.54 & 0.60 & 0.51 \\
\hline Control (s) & - & - & 4.54 & 2.65 & 2.91 & 2.62 & 0.75 & 1.00 \\
\hline
\end{tabular}


Fig. 10 Generator 5 at area 2

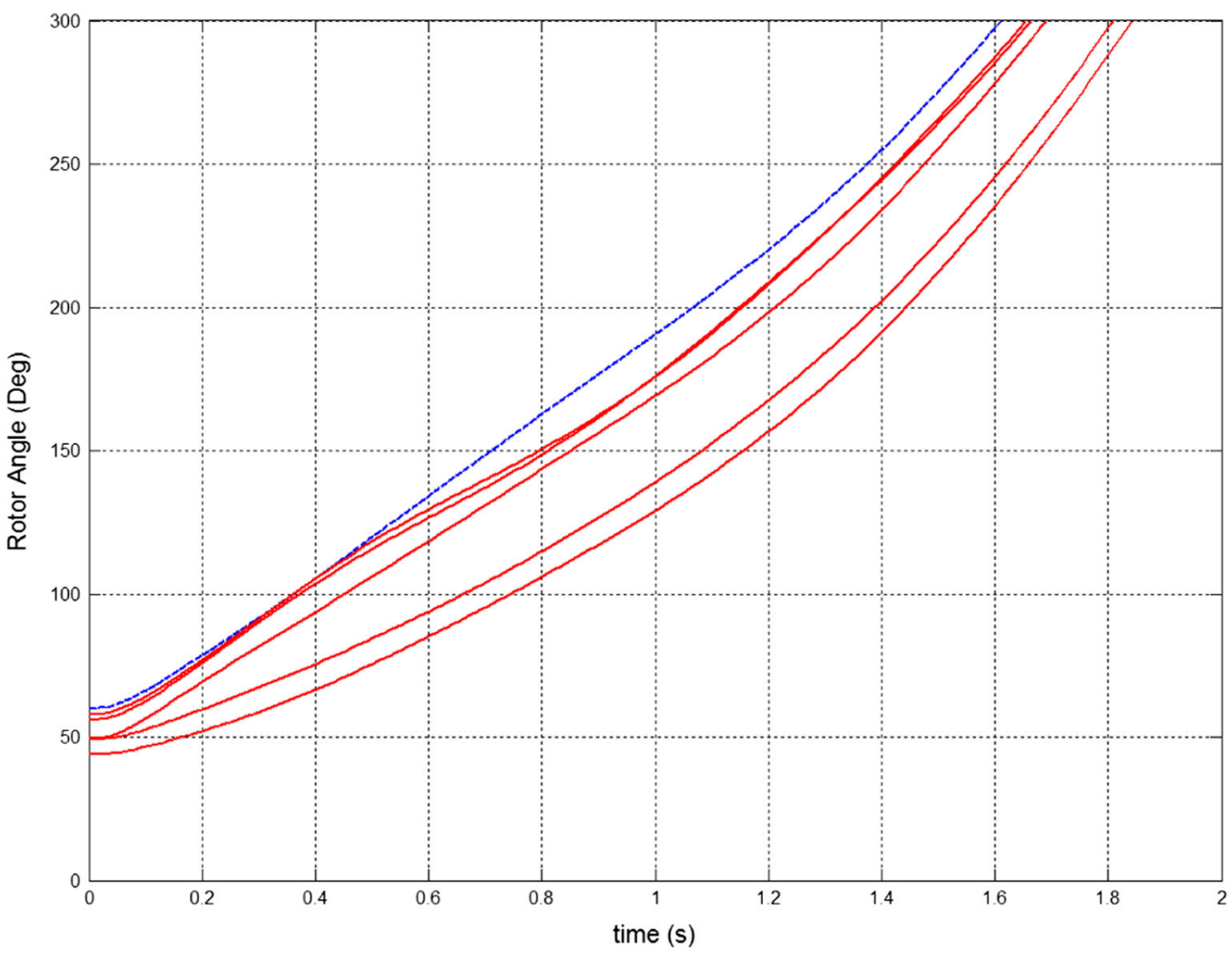

Fig. 11 Generator tripping implemented at $2.65 \mathrm{~s}$

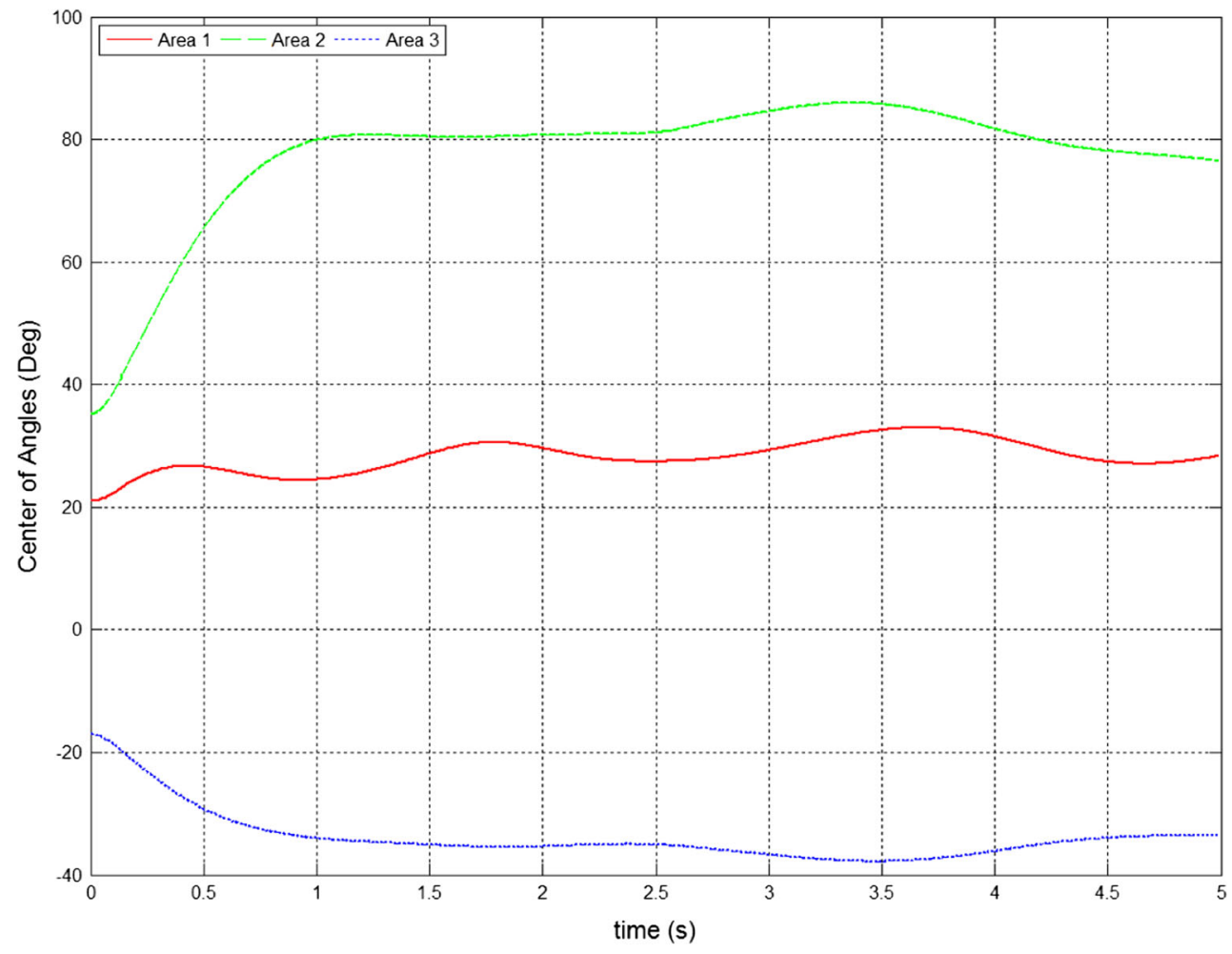


Fig. 12 Generator tripping implemented at $0.75 \mathrm{~s}$

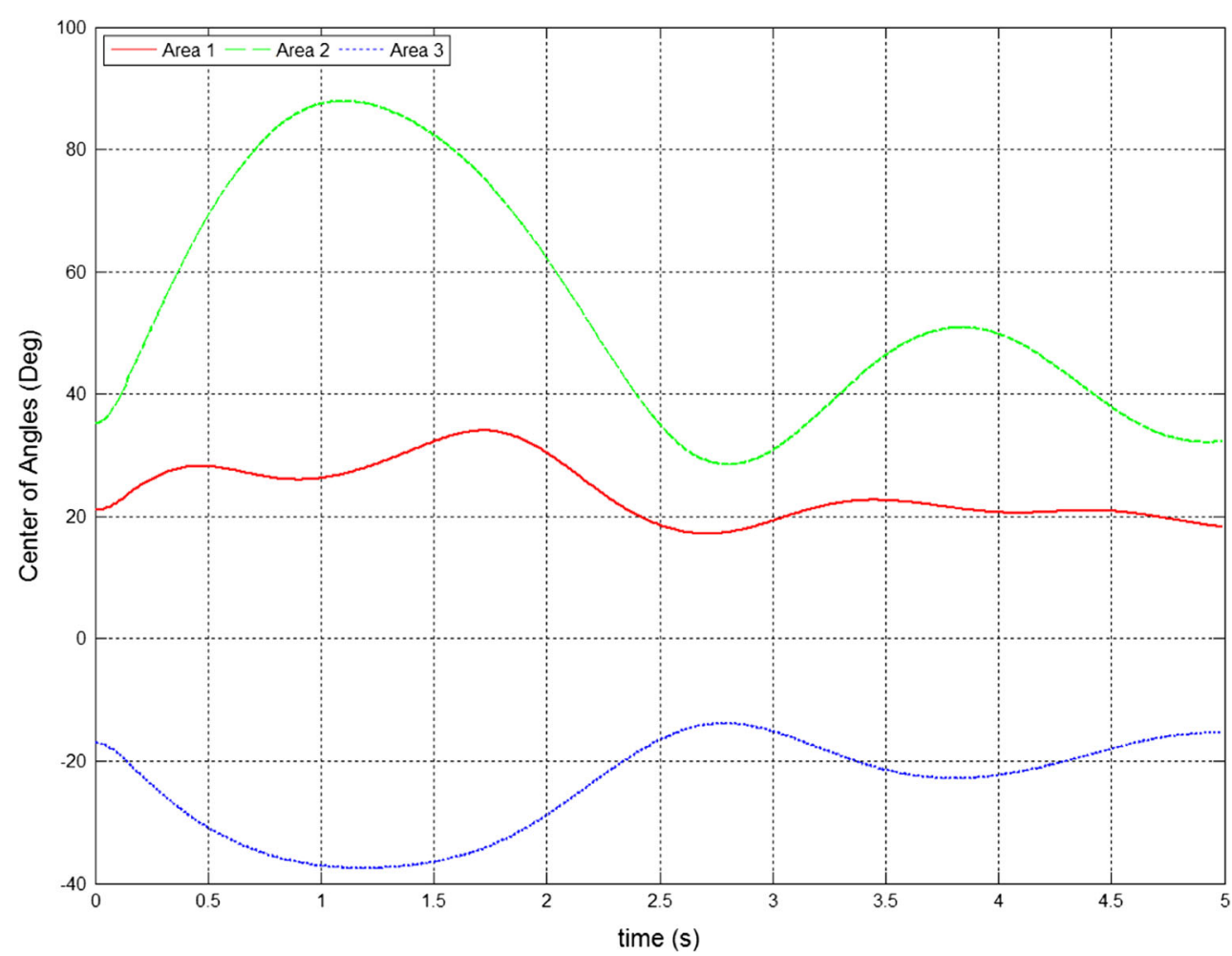

By simulating a three phase fault with a clearing time at $60 \mathrm{~ms}$ and tripping generator 5 in area 2 at $2.65 \mathrm{~s}$ as indicated in Table 1 we observed that the network stabilized. In Fig. 11 it can clearly be seen that the network recovers and does not go OOS thus, improving the network stability without implementing any load shedding.

By creating a three-phase fault at bus 16 with a clearing time of $70 \mathrm{~ms}$; Table 1 shows that area 3 goes OOS first but, area 2 is the first area breaching our threshold thus, a control should be implemented at area 2. By tripping generator 5 in area 2 at 0.75 $\mathrm{s}$, as calculated according to the CCT, we can see in Fig. 12 that the entire network is recovered and did not go OOS.

Thus, by implementing a generator tripping control, load shedding was not required to stabilize the network.

\section{Critical Clearing Time Case Studies}

The case studies laid out in Section "Implementation of the Proposed Algorithm" will now be simulated using the CCT approach to determine the robustness and accuracy of the method. Sections "Determining the Critical Clearing Time" and "Detecting Angle Instability using a Heuristic Rule" focus on the CCT method with the necessary controls to stabilise the network when instability occurs. These two sections use case study three as an example to thoroughly provide all steps and simulation plots. All case studies' results for the CCT, controls required and the specific time the control should be implemented can be seen in Table 2 .

To determine the CCT for case study one, it is required to simulate different fault clearing times to identify the maximum time a three phase fault can occur before the network becomes unstable. In Fig. 13, the network is unstable with a CCT of $120 \mathrm{~ms}$ but is stable in Fig. 14 with a CCT of $110 \mathrm{~ms}$. For this reason, the CCT will be $110 \mathrm{~ms}$ and can establish the supreme value as well as the least value.

By simulating a three phase fault with a CCT of $120 \mathrm{~ms}$, the network is unstable and requires a control scheme to be implemented to stabilize the network. The network stabilizes when generator 9 in area one is tripped at $0.7 \mathrm{~s}$. Figure 15 indicates the stable network after the control scheme was implemented.

Table 2 Case studies results for the IEEE 39 bus network

\begin{tabular}{|c|c|c|c|c|c|}
\hline & CCT & Supreme Value & Least Value & Gen OOS & Control \\
\hline Case Study 1 (Line $26-27)$ & $110 \mathrm{~ms}$ & $60^{\circ}$ & $-32^{\circ}$ & Gen 9 & Area1@0.70s \\
\hline Case Study $2($ Line $8-9)$ & $160 \mathrm{~ms}$ & $90^{\circ}$ & $-46^{\circ}$ & Gen 5 & Area $2 @ 1.20 \mathrm{~s}$ \\
\hline Case Study 3 (Line 16 - 17 ) & $50 \mathrm{~ms}$ & $73^{\circ}$ & $-31^{\circ}$ & Gen 5 & Area $2 @ 2.65 \mathrm{~s}$ \\
\hline Case Study 4 (Line 26 - 29 ) & $80 \mathrm{~ms}$ & $51^{\circ}$ & $-28^{\circ}$ & Gen 9 & Area1@0.90s \\
\hline
\end{tabular}


Fig. 13 Angles of areas at 120 ms CCT

Fig. 14 Angles of areas at 110 ms CCT
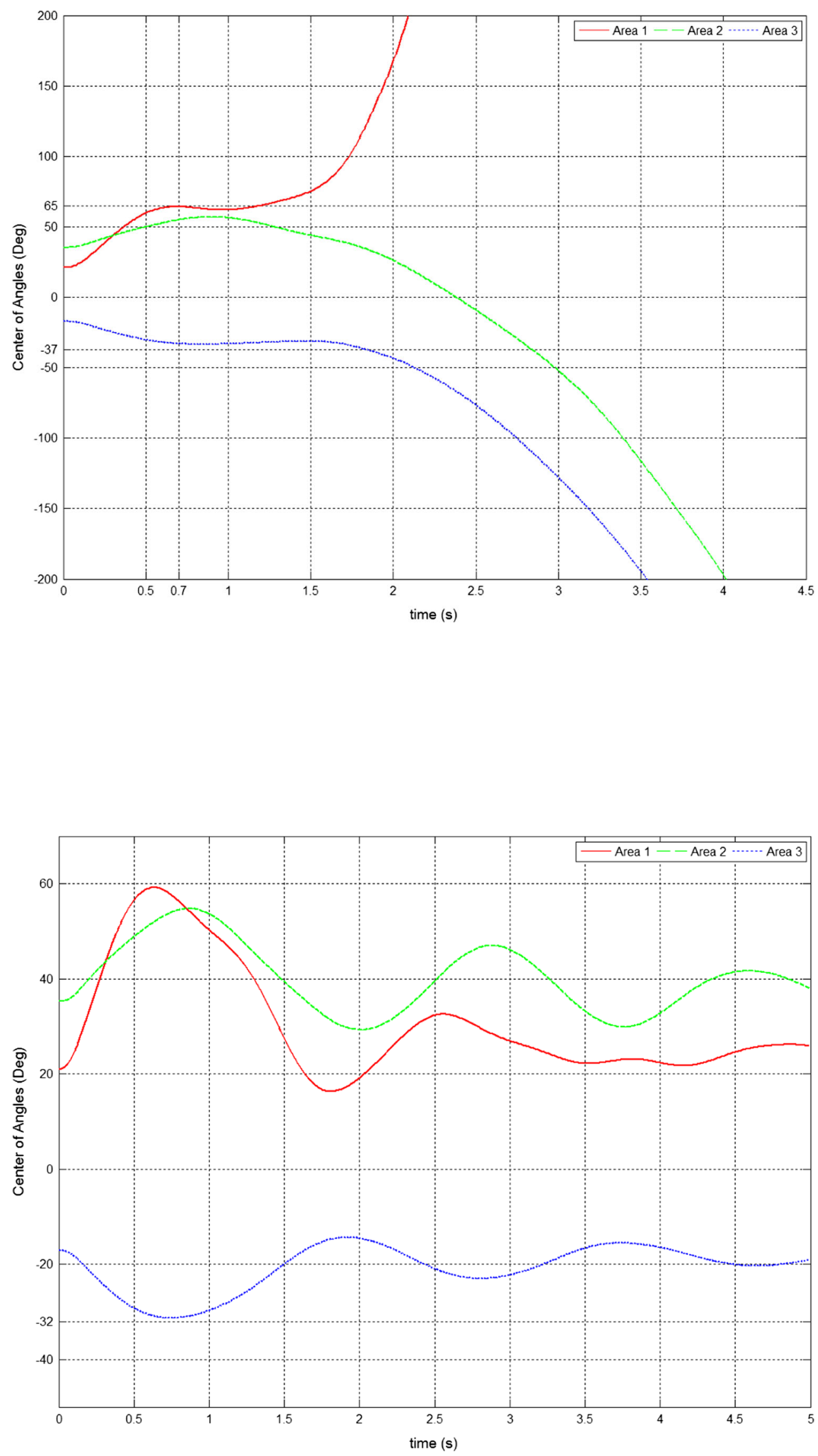
Fig. 15 Angles of areas at 120 ms CCT with control

implemented

Fig. 16 Angles of areas at 170 ms CCT
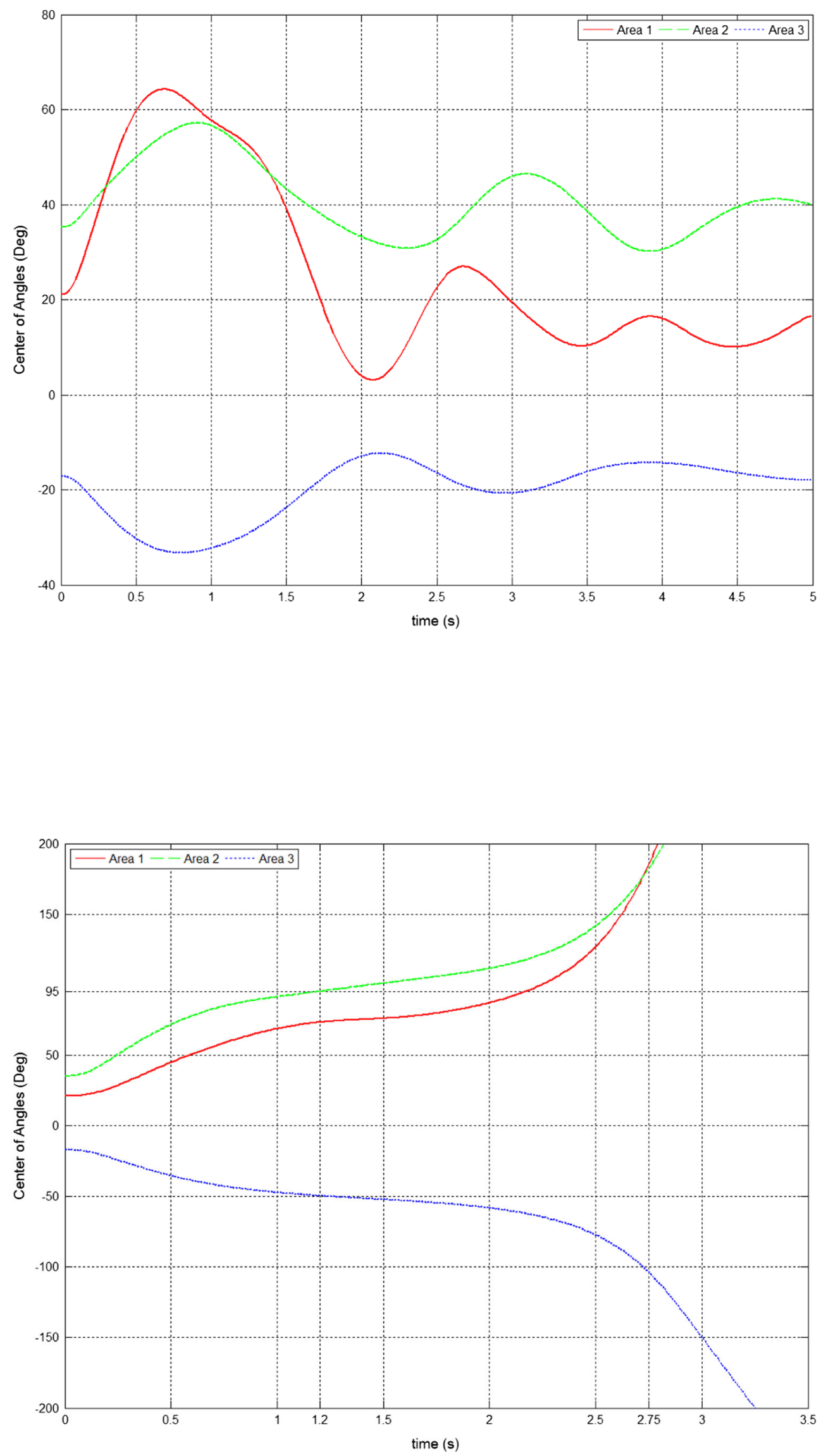
Fig. 17 Angles of areas at 160 ms CCT

Fig. 18 Angles of areas at 170 ms CCT with control implemented
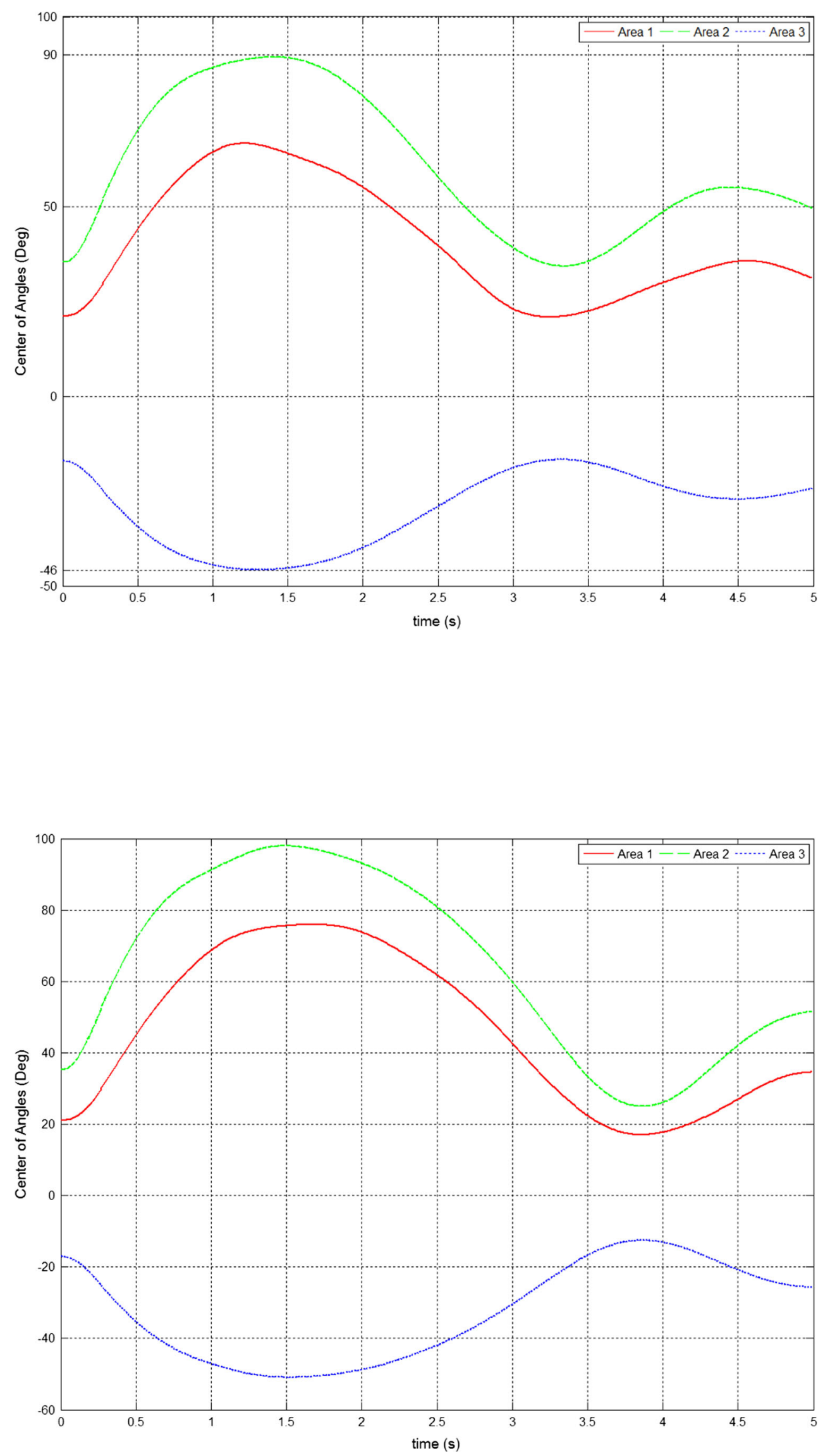
Fig. 19 Angles of areas at 90 ms CCT

Fig. 20 Angles of areas at 80 $\mathrm{ms}$ CCT
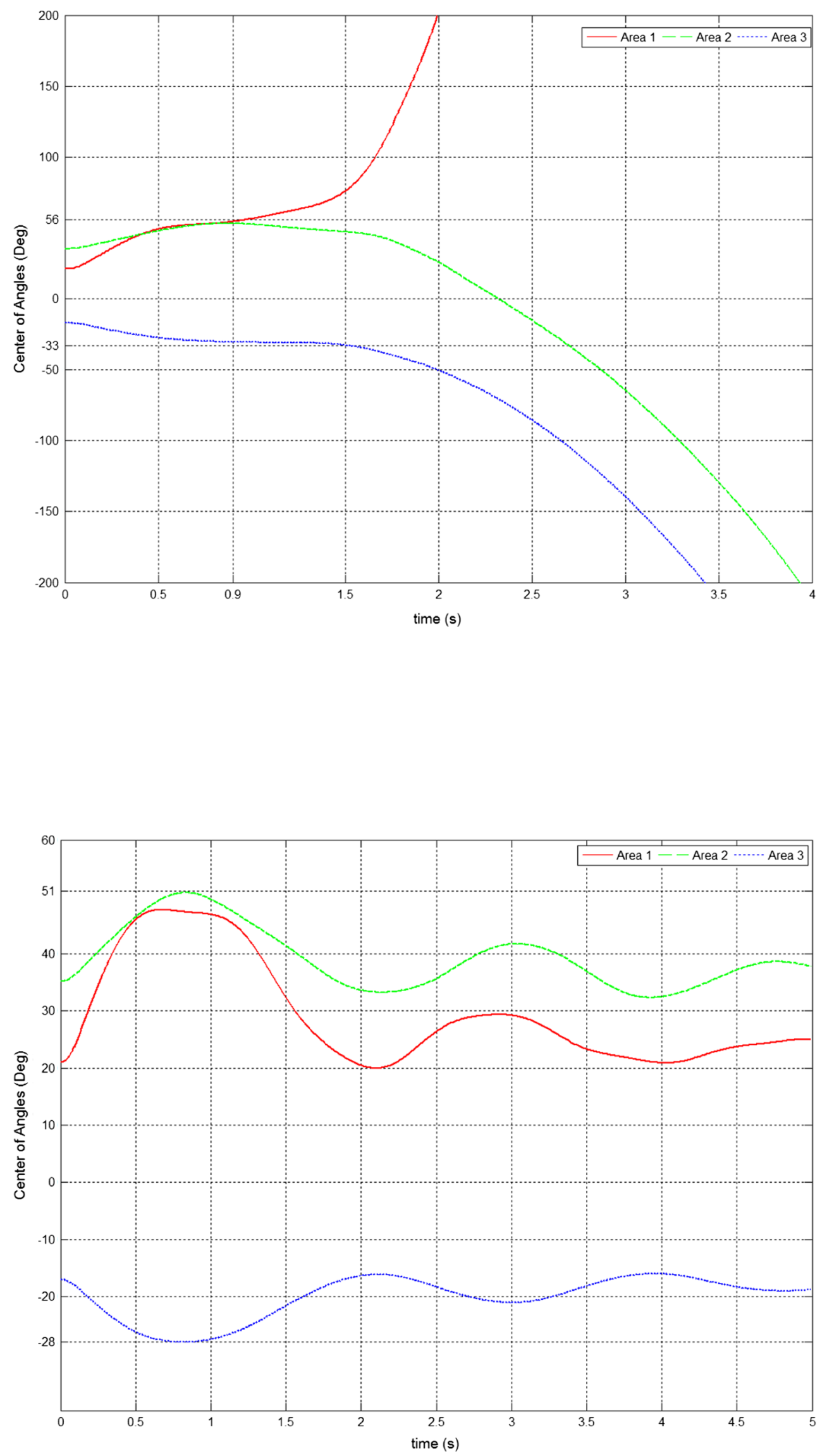
Fig. 21 Angles of areas at 90 ms CCT with control implemented

Fig. 22 Angles of areas at 120 ms CCT with control implemented
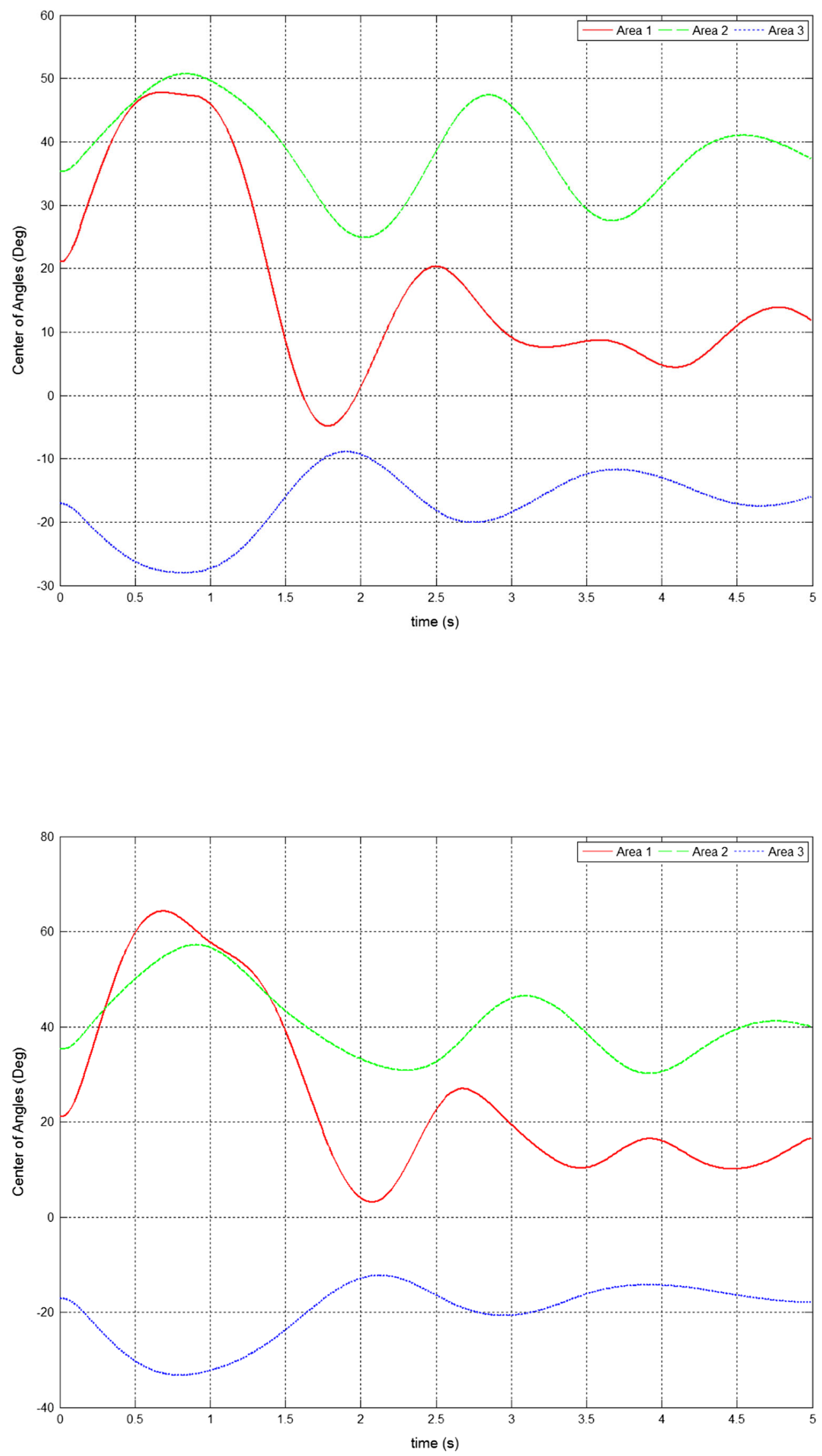
Fig. 23 Case study 1 with control implemented with three faulty PMUs

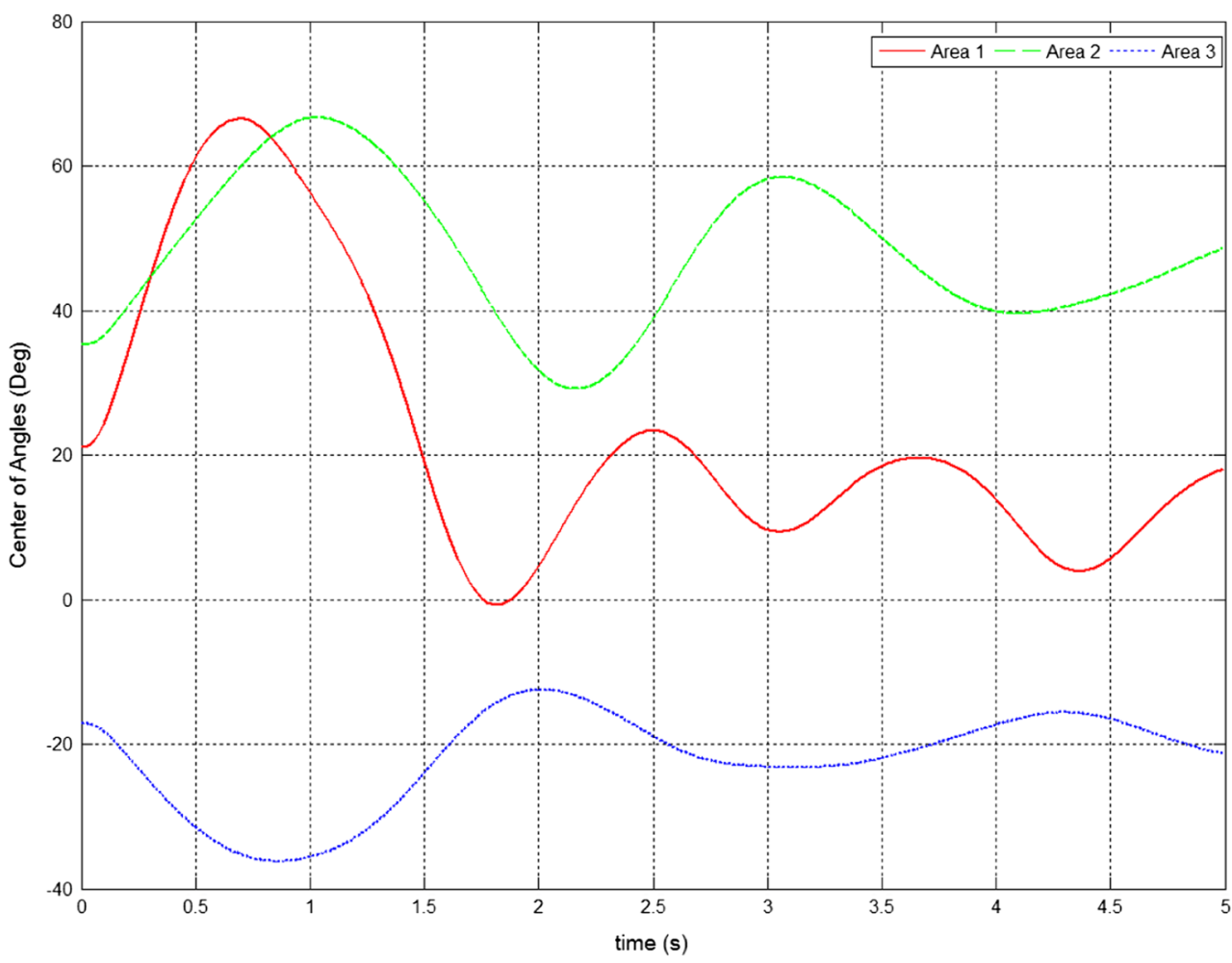

For case study two, the network is unstable in Fig. 16 below with a CCT of $170 \mathrm{~ms}$ but is stable in Fig. 17 with a CCT of $160 \mathrm{~ms}$. Because of the conclusion that the CCT is $160 \mathrm{~ms}$, the supreme value and the least value can be established.

With a CCT of $170 \mathrm{~ms}$, the network is unstable and requires a control scheme to be implemented to stabilize the network. As seen in Fig. 18, by tripping generator 5 in area two at $1.2 \mathrm{~s}$, the network stabilizes.

Case study three was simulated in Sections "Determining the Critical Clearing Time" and "Detecting Angle Instability using a Heuristic Rule" with all results plotted and discussed in detail. The final case study to be simulated is case study four. The network is unstable in Fig. 19 with a CCT of $90 \mathrm{~ms}$ but is stable in Fig. 20 with a CCT of $80 \mathrm{~ms}$. This means that the CCT of this case study is $80 \mathrm{~ms}$. Because the $\mathrm{CCT}$ is known, the supreme value and the least value can be determined.
With a CCT of $90 \mathrm{~ms}$, the network is unstable and requires a control scheme to be implemented for the network to become stable. As seen in Fig. 21, by tripping generator 9 in area one at $0.9 \mathrm{~s}$, the network stabilizes.

\section{Critical Clearing Time with faulty PMUs}

The case studies set out in Section "Implementation of the Proposed Algorithm" will now be simulated using the CCT approach where some of the PMUs sending all relevant information to the local data concentrator will not be functional. In Section "Critical Clearing Time Case Studies", all final plots where the controls were implemented to stabilize the network will be used to indicate if the network remains in its stable state.

Again a table will be generated to provide us with all relevant information. The reason for this test is to indicate if the method used is robust enough and to what level.

Table 3 Case studies results for the IEEE 39 bus network with faulty PMUs

\begin{tabular}{lll}
\hline & CCT After Control Implemented & Load Removed before Instability occurred (MVA) \\
\hline Case Study 1 (Line 26 - 27) & $120 \mathrm{~ms}$ & Load $>=158+\mathrm{j} 30$ \\
Case Study 2 (Line 8 -9) & $170 \mathrm{~ms}$ & Load $>=214+\mathrm{j} \mathrm{48}$ \\
Case Study 3 (Line 16 - 17) & $60 \mathrm{~ms}$ & $\mathrm{Load}>224+\mathrm{j} \mathrm{47.2}$ \\
Case Study 4 (Line 26 - 29) & $90 \mathrm{~ms}$ & Load $>391.8+\mathrm{j} \mathrm{114}$ \\
\hline
\end{tabular}


Figure 22 is the result obtained in Section "Critical Clearing Time Case Studies" case study one with a control implemented to stabilize the network. By creating a scenario where PMUs are faulty, the robustness of the CCT method used will be tested. The longer the system can stay stable with PMUs failing, the better.

As seen in Fig. 23, when three PMUs were faulty and the software could not retrieve the information, the results were incorrect. Case study one was used as an example, the rest of the case studies results can be found in Table 3 .

\section{Conclusion}

In the research conducted, the critical clearing time (CCT) of the specific fault and its location was found. When a fault lasts longer than the specific CCT a control is implemented to prevent the network from going out-of-step (OOS). It was found that if the control is implemented $1 \mathrm{~ms}$ too late, the network will go OOS and will loose synchronism with the rest of the generators in the power system. Four scenarios were created to indicate the robustness of the proposed method. The paper was extended by simulating faulty PMUs at different locations while a transient fault was created and rectified with a control to prove the stability and performance of the proposed method.

\section{References}

1. Kundur P, Balu NJ, Lauby MG (1994) Power system stability and control, vol 7. McGraw-hill, New York

2. Bhat S, Bansal RC, Bhatti TS (2009) Methods of power system transient stability enhancement. Int J Integr Energy Syst 1(1):37-46

3. Pavella M, Ernst D, Ruiz-Vega D (2000) Transient stability of power systems: a unified approach to assessment and control, vol 581. Springer Science and Business Media

4. Farhangi H (2010) The path of the smart grid. IEEE Power Energy Mag 8(1):18-28

5. Amin SM, Wollenberg BF (2005) Towards a smart grid: power delivery for the 21st century. IEEE Power Energy Mag 3(5):34-41

6. Ning JA, Liu X, Venkatasubramanian VM (2013) Distributed real-time stability monitoring algorithms using synchrophasors. In: Bulk power system dynamics and control-IX; optimization, security and control of the emerging power grid, pp 1-5

7. Brown H, Happ H, Person C, Young C (1965) Transient stability solution by an impedance matrix method. IEEE Trans Power Apparatus Syst PAS-84(12):1204-1214

8. Sherwood M, Hu D, Venkatasubramanian VM (2007) Real-time detection of angle instability using synchrophasors and action principle. In: Bulk power system dynamics and control-VII. Revitalizing operational reliability. IREP Symposium, pp 1-11

9. Wang Z, Aravnthan V, Makram EB (2011) Generator cluster transient stability assessment using catastrophe theory. In: 10th Int. conf., environment and electrical engineering (EEEIC), pp 1-4
10. Zhou DQ, Annakkage U, Rajapakse AD (2010) Online monitoring of voltage stability margin using an artificial neural network. IEEE Trans Power Syst 25(3):1566-1574

11. Yan P, Sekar A, Rajan P (2000) Pattern recognition techniques applied to the classification of swing curves generated in a power system transient stability study. In: Southeastcon Proc. of the IEEE, pp 493-496

12. Chang C, Srinivasan D, Liew A (1994) A hybrid model for transient stability evaluation of interconnected longitudinal power systems using neural network/pattern recognition approach. IEEE Trans Power Syst 9(1):85-92

13. De La Ree J, Centeno V, Thorp JS, Phadke AG (2010) Synchronized phasor measurement applications in power systems. IEEE Trans Smart Grid 1(1):20-27

14. Guzmán A, Mynam V, Zweigle G (2007) Backup transmission line protection for ground faults and power swing detection using synchrophasors. In: Proc. of the 34th Annual western protective relay conf. Spokane

15. Glavic M, Van Cutsem T (2011) A short survey of methods for voltage instability detection. In: IEEE Power and energy society general meeting, pp 1-8

16. Schweitzer E, Whitehead D, Guzman A, Gong Y, Donolo M (2008) Advanced real-time synchrophasor applications, in 35th Annual Western Protective Relay Conf., Spokane, Washington USA

17. Mulhausen J, Schaefer J, Mynam M, Guzmán A, Donolo M (2010) Anti-islanding today, successful islanding in the future. In: IEEE Protective relay engineers 63rd annual conf., pp 1-8

18. Pena P, Etxegarai A, Valverde L, Zamora I, Cimadevilla R (2013) Synchrophasor-based anti-islanding detection. In: IEEE PowerTech, pp 1-6

19. Hu D, Venkatasubramanian V (2007) New wide-area algorithms for detection and mitigation of angle instability using synchrophasors. In: IEEE Power engineering society general meeting, pp $1-8$

20. Abdul Wahab NI, Mohamed A (2012) Area-based COI-referred rotor angle index for transient stability assessment and control of power systems. In: Abstract and applied analysis, p 23

21. Hashim H, Zulkepali M, Omar Y, Ismail N, Abidin I, Yusof S (2010) An analysis of transient stability using center-of-inertia: angle and speed. In: IEEE Int. conf. power and energy (PECon), pp 402-407

22. Karady GG, Gu J (2002) A hybrid method for generator tripping. IEEE Trans Power Syst 17(4):1102-1107

23. Baydokhty ME, Eidiani M, Zeynal H, Torkamani H, Mortazavi H (2012) Efficient generator tripping approach with minimum generation curtailment based on fuzzy system rotor angle prediction. Przeglảd Elektrotechniczny 88:266-271

24. Chen C-R, Tsai W-T, Lee C-Y, Lin Z-F (2011) SPS generator tripping planning using immune algorithm. In: 16th IEEE International conf. intelligent system application to power systems (ISAP), pp 1-4

25. Wang Z, Aravnthan V, Makram EB (2011) Generator cluster transient stability assessment using catastrophe theory. In: 10th Int. Conf. environment and electrical engineering (EEEIC), pp 1-4

26. Yusof S, Rogers G, Alden R (1993) Slow coherency based network partitioning including load buses. IEEE Trans Power Syst 8(3):1375-1382

27. Taylor CW, Erickson DC, Martin KE, Wilson RE, Venkatasubramanian V (2005) WACS-wide-area stability and voltage control system: R\&D and online demonstration. Proc IEEE 93(5):892906 